\title{
Understanding the Intention to Adopt Cloud-based Accounting Information System in Jordanian SMEs
}

Abdalwali Lutfi. College of Business, King Faisal University, Saudi Arabia, aalkhassawneh@kfu.edu.sa

\begin{abstract}
The Information Technology (IT) revolution that led to the development of cloud computing services and systems has brought numerous benefits to end users handling business through the Internet, particularly in the field of accounting information systems (AIS). Cloud-based accounting information systems (CB-AIS) enable firms to substantially reduce their investment in IT and have flexible access to an enormous group of current and scalable resources. CB-AIS enables small- and medium-sized enterprises (SMEs) to undertake basic bookkeeping responsibilities themselves instead of paying external auditors for the same services. In Jordan, however, current businesses are still in the infancy stage when it comes to CB-AIS adoption. Therefore, this study applied the Technology, Organization, and Environment model to examine CB-AIS adoption among SMEs in Jordan. Data collection was achieved using a structured survey questionnaire collected from 156 owners/managers of SMEs in Jordan through online means. The proposed research framework comprises six factors that influence intention to adopt CB-AIS (IACB-AIS). Based on the findings, the proposed hypotheses were supported in that the factors positively and significantly affect the IACB-AIS of SMEs in Jordan. Through examining an actual IACB-AIS case and highlighting the importance of its application, the study and its findings are expected to contribute to decision-makers and practitioners in the IT field.
\end{abstract}

Keywords: CB-AIS, intention to adopt, TOE framework, security concern, SMEs. 


\section{INTRODUCTION}

Information and Communication Technology (ICT) is used extensively all over the globe by businesses of various sizes owing to the dynamic changes and challenges in the business environment (Alsyouf, 2021; Khayer et al., 2020; Lutfi et al., 2021). Such businesses include small- and medium-sized enterprises (SMEs), which constantly face logistical determinants and challenges compared to other enterprises of other sizes, like large-sized businesses. These challenges among SMEs have been attributed to their smaller number of employees and lower budget allocation (Usman et al., 2019). This situation makes their computing environment less complicated than those of major enterprises even though their demand experiences are similar (Asatiani et al., 2019; Ma et al., 2021). Accordingly, there is an urgent need for SMEs to develop their level of services to achieve their goals in terms of controlling, monitoring, reduction of production costs, purchasing of materials, controlling levels of inventory, and usage of resources. SMEs are expected to make use of activities that meet the requirements of their Information Technology (IT) department (Lutfi et al., 2016).

Evidently, SMEs have begun using accounting information systems (AIS) to develop their competitiveness in the market, minimize costs, enhance management, provide effective services, improve functionalities of management, and make fewer errors (Lutfi et al., 2016; Lutfi, 2020; Buntin et al., 2011). AIS refers to an information systems (IS) or IT tool that functions to support financial and accounting data collection, storage, and processing for management to carry out decision making (Faccia \& Petratos, 2021). The AIS improves the coordination level among different units of function in SMEs, and literature has provided insight into the need for IT support among business processes (Alshirah et al., 2021; Aldmour et al., 2016). In other words, SMEs require AIS implementation to establish higher competence and efficiency levels. Traditional means of AIS usage have weaknesses that enterprises have to deal with, such as high licensing and software package installation costs; this situation holds true for SMEs (Ma et al., 2021). Moreover, traditional AIS packages are too complex for SMEs to use for several reasons, including the structural make up that is characterized by hardware costs and maintenance, lack of IT infrastructure, lack of IT specialists to bring about smooth AIS implementation, and mitigated IT budget among enterprises (Le \& 
Cao, 2020). Thus, adopting a required premise that consumes less time and costs is more feasible and effective than using conventional AIS.

Since its inception, the AIS field has undergone dynamic changes through the development of cloud-based accounting information systems (CB-AIS) (Ma et al., 2021; Asatiani et al., 2019), which allow businesses to utilize third-party hosting of IT resources and applications through virtual means as opposed to physical means (Le \& Cao, 2020; Sutthikun et al., 2018). Consequently, the need to install software modules in adopter PCs or data storage in local servers does not exist, leading to lower hardware investments and fees (Popivniak, 2019). More importantly, CBAIS usage reflects a technique that saves considerable power through the employment of solid-state discs as opposed to conventional hard discs (Berl et al., 2010; Khayer et al., 2020). Aside from the above benefits, CB-AIS is also better than traditional IS as it enables a firm's easy access to reasonably priced IS featuring improved capabilities of data processing, real-time collaboration functionalities, and enhanced accessibility (Asatiani et al., 2019; Asatiani \& Penttinen, 2019). Thus, CB-AIS adoption is bound to affect accounting configurations through the provision of a platform where both the client firm and accounting firm can work on process and data, paving new ways toward work organization by using outsourcing connections. In a related study, Rohde (2004) stated that CB-facilities are affordable and flexible, which make them attractive to SMEs that possess confined resources and expertise. Thus, Sultan (2011) emphasized on the importance of these facilities as part of the business productivity and competitive advantage extension. Based on the above reasons, CB-AIS can be viewed as an affordable alternative that would be feasible and beneficial for SMEs to adopt and utilize in comparison to conventional AIS.

Popivniak (2019) also explained that the implementation of CB-AIS within SMEs would benefit them in terms of accurate data collection, integration, recording, and management, with information collected throughout the entire enterprise functional units and business departments to realize set aims, targets, and objectives. SMEs can leverage CB-AIS and the computing diffusion system to execute data transactions throughout value chain activities and break down information for inventory, finance, planning, manufacturing, sales, distribution, materials, human resources, marketing, engineering, and all other operations in the business enterprises (Alshirah et al., 2021; Aini et al., 2020). In this regard, SMEs do not 
have to obtain IT infrastructure but can lease hardware and pay for the obtained services. This means that cloud computing services can generate savings for SMEs and increase their agility and versatility in terms of operations (both external and internal) while minimizing the costs of production (Lutfi, 2021).

Literature dedicated to the topic has investigated the effect of CB-AIS adoption among SMEs, yet only a few have delved into such adoption in the same context from an extensive picture covering technological, organizational, and environmental factors (Alshirah et al., 2021; Hsu et al., 2014). Awareness is still lacking concerning the logistical determinant factors that have a key role in affecting CB-AIS adoption decision among SMEs in developing economies (Ma et al., 2021; Lutfi, 2021). SMEs are the emerging markets for cloud-computing providers and suppliers and have attracted substantial attention as they are considered the driver (lifeblood) of economies, specifically of developing ones. Most of the businesses in developing countries - including Jordan-belong to SMEs. In fact, CB systems such as CB-AIS have large potentials in SMEs that operate in emerging countries such as Jordan. However, there is a lack of research surrounding the logistical determinant factors for cloud-ERP implementation. The ICT implementation culture also faces noteworthy complications within SMEs, including a lack of awareness regarding CB-AIS, which makes them incapable of improving their competitive positions (Alshirah et al., 2021). Accordingly, there is a need to fill this gap through conducting research on SMEs to encourage a culture of CB-AIS implementation in these businesses. To the author's knowledge, no work has been conducted to measure the factors influencing CB-AIS adoption in SMEs, especially in the Jordanian context. The current work chooses to concentrate on manufacturing SMEs in Jordan because of the role and importance of this sector in achieving economic growth.

This study expands the scope of existing cloud computing literature. It mainly aims to examine the adoption of CB-AIS among Jordanian manufacturing SMEs and identify the main driving factors influencing such adoption. Practically, it assists SME owners/managers as they have a clear idea of the significant role of $\mathrm{CB}$ systems adoption in enhancing the productivity, competitiveness, and performance in their industries. Finally, this study offers relevant guides to the importance of CB-AIS adoption among manufacturing SMEs. 
The remainder of this paper is organized as follows. Section 2 introduces the theoretical framework and hypothesis development. Section 3 discusses the methodology of the study. Section 4 displays the results of data analysis and interpretation. Section 5 illustrates the discussion. The last section discusses the conclusions, limitations, and further research of this study.

\section{THEORETICAL FRAMEWORK AND HYPOTHESIS DEVELOPMENT}

The Technology, Organization, and Environment (TOE) model is the underpinning model adopted in this study. It sets a classification for technological, organizational and environmental factors as the three influencing factors that lead to decisionmakers' adoption/rejection of an innovation (Low et al., 2011). The TOE model has been proven to have robust empirical support, a strong theoretical basis, and extensive application in examining innovation implementation and adoption (Oliveira et al., 2019). The present work classifies the constructs within the model by reviewing literature relevant to IT/IS adoption and implementation among SMEs. As a consequence, numerous factors that have the potential to influence CBAIS adoption by SMEs were categorized (Alshirah et al., 2021). The factors in each of the three major contexts are described in detail in the next subsections, followed by the formulation of hypotheses.

\subsection{Technological constructs}

Prior studies on IT and IS adoption (Khayer et al., 2020; Ramdani et al., 2009; Lutfi et al., 2017; Lutfi et al., 2016) that used the TOE framework to examine the phenomenon in SMEs have evidenced that organizations' technological attributes manage to explain the IT/IS innovation characteristics that influence the decisions toward their adoption (Lutfi et al., 2022; Thong, 1999). Thus, this study selects perceived usefulness (PU) and security concern (SC) from the technological constructs.

\subsubsection{Perceived usefulness}

Davis (1989) described PU as the level to which decision-makers are convinced that adopting a particular technology could enhance the performance of the organization. Moreover, TAM hypothesizes PU as having a direct influence on the behavioral intention toward adopting a certain IT or IS (Al-Okaily et al., 2020b; AlOkaily et al., 2020c; Alsyouf et al., 2021), and this was supported by prior studies (Alsyouf et al., 2021; Elkaseh et al., 2016; Jamal \& Sharifuddin, 2015; Makena, 
2013). PU has actually been investigated extensively in light of varying IT and IS adoption and was found to be positive and significant, including in the adoption of social media (Siamagka et al., 2015), mobile service provider (Abbas \& Hamdy, 2015), and digital payment system (Al-Okaily et al., 2020a).

Thus, this paper formulates the following hypothesis for testing.

H1. Perceived usefulness has a positive and significant influence on intention to adopt CB-AIS.

\subsubsection{Security concern}

The level at which an internet platform is expected to be of concern for data exchange and carrying out interactions online is referred to as SC. At present, there is a marked increase in security issues owing to the complexity of computer networks (Lutfi et al., 2022; Sahandi et al., 2012). Security risks in the form of data interception, viruses, and hacking have been highlighted as the primary concern when conducting businesses online (Sahandi et al., 2012; Salum \& Rozan, 2016). Works on SC examination in the case of cloud computing among SMEs are numerous. Among them is the study of Zhu et al. (2006), who conducted a survey involving 1415 firms in six European countries in their attempt to examine the innovation characteristics that may be related to the adoption of e-business (EB) by enterprises. The authors found a negative SC-EB adoption relationship.

In addition, Fillis et al. (2004) focused their study on 21 SMEs in the UK and concluded that SC had the potential to prevent e-commerce adoption. The general belief is that $\mathrm{SC}$ would delay the adoption of e-commerce among businesses (Salum \& Rozan, 2016), and so the construct needs to be investigated in the context of cloud computing adoption among SMEs. This study proposes the following hypothesis for testing.

H2. Security concern has a significant and negative influence on intention to adopt $C B-A I S$.

\subsection{Organizational constructs}

The TOE framework posits that innovation adoption by an organization could be affected by the constructs of the organization, indicating that the attributes of the organization have the potential to influence its decisions regarding technology adoption (Khayer et al., 2020). The current study considers two characteristics of 
organizational factors when it comes to CB-AIS adoption in SMEs, namely, top management support (TMS) and organizational readiness (OR).

\subsubsection{Top management support}

According to Lutfi et al. (2022), TMS is the support that higher-level management provides toward the acceptance and adoption of innovation technology for business purposes. Moreover, TMS is considered to be among the top critical predictors of IT/IS adoption at the organizational level (Jeyaraj et al., 2006; Khayer et al., 2020; Lutfi et al., 2017). Studies dedicated to innovation adoption using the TOE framework support the positive and significant impact of TMS on the decision of organizations regarding innovation adoption/acceptance (Low et al., 2011; Lutfi et al., 2017; Ramdani et al., 2009). It is thus expected that businesses with a high level of support from top management are likely to adopt CB-AIS. Consequently, this study proposes the following hypothesis.

H3. Top management support has a significant and positive influence on intention to adopt $C B$-AIS.

\subsubsection{Organizational readiness}

OR is the level of available resources (financial and technical) that an organization has to accept/adopt technology (Almaiah et al., 2021; Lutfi et al., 2017). OR was proven to have a positive and significant influence over the decision of an organization to adopt innovation (Rogers, 1995; Lutfi et al., 2016). Specifically, Fathian et al. (2008) conducted a review of assessment models of e-readiness and highlighted the critical factors for evaluating SMEs' e-readiness. The authors found that OR significantly predicts SMEs' adoption of IT and IS. In Daoud and Ibrahim (2019), the e-procurement status among Jordanian and U.S. firms was investigated, and the results supported OR as a significant e-procurement adoption predictor in this context. Thus, the above discussion leads to the current study's formulation of the following hypothesis.

H4. Organizational readiness has a positive and significant influence on intention to adopt $C B$-AIS.

\subsection{Environmental constructs}

In the TOE model, the environmental construct encapsulates the structure of the industry, the availability of the technologies provider, and the business dogmatic 
environment (Awa et al., 2016; Oliveira et al., 2014). According to Scupola (2003), innovation can be influenced by the supported technologies infrastructure while Alshirah et al. (2021) and Lutfi et al. (2020) indicated that the availability of skilled workers/consultants and technology service suppliers all work toward stimulating innovation. TOE model's environmental construct provides insight into the influence of pressures from the external environment on the technology adoption of organizations (Gutierrez et al., 2015; Lutfi et al., 2020). In the present study, two technology attributes in the environmental domain are considered to explain changes in the intention to adopt CB-AIS (IACB-AIS) among SMEs, namely, competitive pressure (CP) and supplier computing support (SCS).

\subsubsection{Competitive pressure}

This type of pressure is the level of pressure that businesses experience from their rivals, which incentivizes businesses to adopt innovations in order to prevent failure to compete (Lutfi et al., 2020). Through CB-AIS adoption, business can have an optimum view of the markets, enhance their productivity and operational competence, and eventually increase their competitiveness (Alshirah et al., 2021; Misra \& Mondal, 2011). In relation to this, firms working at a medium level of competitiveness are the ones that have a higher likelihood to adopt CB systems. New technology is adopted and used by firms with the conviction that their competitors are also adopting it, which means that the adoption of new technologies from rivals boost the SMEs' consideration of technology adoption (Usman et al., 2019). Various studies have looked into the effect of CP on new technology adoption and evidenced its significance (Alshirah et al., 2021; Lutfi et al., 2016; Lutfi et al., 2017). CP can boost the positive adoption intention of SMEs when it comes to CB-AIS. Thus, this study hypothesizes the following:

H5. Competitive pressure has a positive and significant influence on intention to adopt $C B-A I S$.

\subsubsection{Supplier computing support}

The success of $\mathrm{CB}$ technologies implementation requires support from suppliers (Khayer et al., 2020), because partner relationships are critical determinants of the acceptance/adoption of inter-organization systems. In addition, powerful suppliers can use IT/IS strategies to encourage trading partners to accept and adopt innovation (Iacovou et al., 1995; Khayer et al., 2020), and with expert suppliers, 
businesses will likely engage in accepting technologies (Maqueira-Marín et al., 2017; Simatupang \& Sridharan, 2005). With the same line of argument, Frambach et al. (1998); Hsu et al. (2014); and Woodside and Biemans (2005) enumerated the composition of the support provided by cloud providers as follows: training, support, marketing, technical customer service, and troubleshooting. The expected risks of the potential customer can be reduced by highlighting the significance of the supplier's activities (e.g., communication and targeting). Service providers also have to provide a support agreement, carry out constant system testing and maintenance, ensure data integrity, and assure customers of the prevention of losses through the establishment of $24 / 7$ centres for assistance. The findings discussed above lead the study to formulate the following hypothesis,

H6. Supplier computing support has a positive and significant influence on intention to adopt $C B$-AIS.

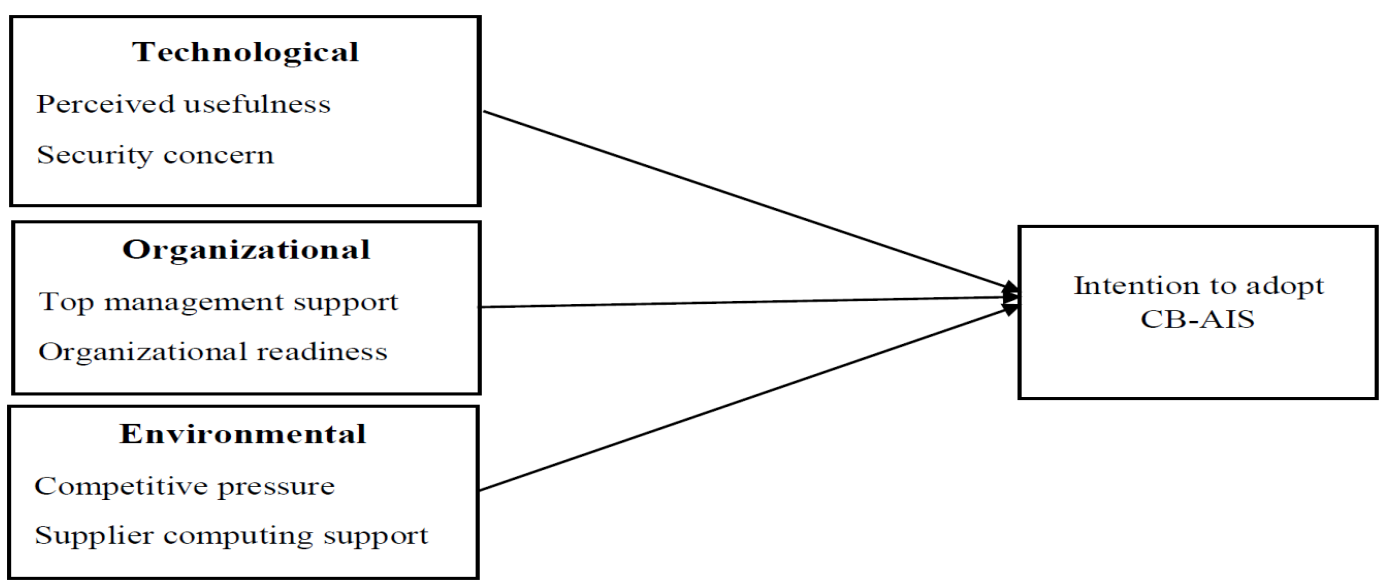

Figure 1. Highlights of the proposed model

\section{METHODOLOGY}

\subsection{Measurements, sampling, and data collection}

The theoretical construct of this study is assessed using a questionnaire survey distributed to manufacturing SMEs in Jordan. The survey questionnaire was developed to include items based on relevant past literature. To ensure consistency with the sources, the study constructs (PU, SC, TMS, OR, CP, and SCS) were measured on a five-point Likert scale ranging from "strongly disagree" represented by 1 to "strongly agree" represented by 5 . An online survey was opted for because it is easily accessible and maximizes the likelihood of data collection success. The 
author ensured that the survey could be accessed 24/7, and a link was provided to the respondents within a three-month period.

Prior to the actual study, a pilot study was conducted on the instrument by distributing it to 40 SMEs that responded voluntarily to the request and were later excluded from the actual survey. The findings of the pilot study established the validity, reliability, and translation equivalence of the scale (Alshira'h \& AbdulJabbar, 2020; Bani-Khalid et al., 2022).

Specifically, the recipients of the survey questionnaire were owners/managers of SMEs who have a major hand in the decision-making process. They were chosen on the basis of the knowledge they hold and their inclination to participate. A total of 500 questionnaires were distributed, from which 173 were retrieved $(35 \%$ response rate). The obtained and prepared dataset comprising 173 records was exposed to the SPSS software package to sort out the corrupt/inaccurate contents of some records, such as duplicate observations, irrelevant observations, structural errors, incomplete records, and missing data. The dataset was scrutinized and cleaned, after which structural errors were rectified and duplicates, along with irrelevant and missing records, were removed. Following the process of data screening, 156 of the 173 records were deemed to be ready for analysis.

\subsection{Data analysis}

Data analysis was conducted using Smart partial least square-structural equation modeling (PLS-SEM), and the analysis results are presented in table and discussion form. The nature of the current work is aligned with that of the approach as it concentrates on the exploration or development of theory as opposed to theory confirmation (Al-Khasawneh et al., 2015; Alshira'h et al., 2020; Alshira'h, 2019; Alqudah et al., 2019; Hair et al., 2019; Reinartz et al., 2009). PLS-SEM is also considered to be suitable for the present study because it considers the complex model and the number of indicators (Al Amri \& Almaiah, 2020: Alshira'h et al., 2021). Lastly, this study attempted to improve data-driven variance explained rather than model fit estimation and, thus PLS-SEM was preferred over covariance-based SEM as recommended by Hair et al. (2019). 


\section{RESULTS AND INTERPRETATION}

\subsection{Measurement model}

The measurement model was evaluated using the criteria of internal reliability (IR), convergent validity (CV), and discriminant validity (DV) (Hair et al., 2019). To begin with, construct reliability is generally measured using Cronbach's alpha; in this study, reliability values exceeded the threshold of 0.70 (Hair et al., 2019) (Table 1). $\mathrm{CV}$ was confirmed by examining the item loadings, composite reliability (CR), and average variance extracted (AVE). The results in Table 1 show that the item loadings and AVE values exceeded the recommended threshold value of 0.50 (Fornell \& Larcker, 1981). CR values were also within the required values $(>0.70)$ (Hair et al., 2019). Next, DV was examined through the measured correlations of possible overlying latent construct. The square root of AVE for each construct was obtained and found to be above the correlations of the constructs and others like it (Table 2), indicating that the study variables had DV (Henseler et al., 2015).

\begin{tabular}{|c|c|c|c|c|}
\hline Latent Construct & $\begin{array}{l}\text { Item Loading } \\
\text { Range }\end{array}$ & $\begin{array}{l}\text { Cronbach's } \\
\text { alpha }\end{array}$ & $\begin{array}{l}\text { Composite } \\
\text { Reliability }\end{array}$ & AVE \\
\hline & $>0.700$ & $>0.700$ & $>0.700$ & $\begin{array}{l}> \\
0.500\end{array}$ \\
\hline Intention to Adopt CB-AIS & $0.865-0.902$ & 0.864 & 0.917 & 0.787 \\
\hline Perceived usefulness & $0.809-0.834$ & 0.842 & 0.893 & 0.678 \\
\hline Security concern & $0.793-0.838$ & 0.827 & 0.885 & 0.657 \\
\hline Top management support & $0.832-0.896$ & 0.817 & 0.891 & 0.731 \\
\hline Organizational readiness & $0.824-0.862$ & 0.859 & 0.904 & 0.703 \\
\hline Competitive pressure & $0.809-0.852$ & 0.849 & 0.899 & 0.688 \\
\hline Supplier computing support & $0.752-0.868$ & 0.758 & 0.860 & 0.673 \\
\hline
\end{tabular}


Based on the values in Table 2, the AVE square roots on the diagonal line are higher compared to the inter-construct correlations, which is indicative of good DV. Taking into consideration all the indicators, it can be concluded that the measurement model achieved the requirements at the level of construct and item. Therefore, the next step is to assess the structural model and test the formulated hypotheses.

\begin{tabular}{lccccccc}
\hline & $\begin{array}{c}\text { IACB- } \\
\text { AIS }\end{array}$ & OR & TMS & SC & PU & CP & SCS \\
\hline IACB-AIS & $\mathbf{0 . 8 8 8}$ & & & & & & \\
OR & 0.751 & $\mathbf{0 . 8 3 9}$ & & & & & \\
TMS & 0.623 & 0.651 & $\mathbf{0 . 7 7 3}$ & & & & \\
SC & 0.535 & 0.710 & 0.523 & $\mathbf{0 . 8 1 0}$ & & \\
PU & 0.692 & 0.677 & 0.549 & 0.649 & $\mathbf{0 . 8 2 4}$ & \\
CP & 0.441 & 0.528 & 0.481 & 0.545 & 0.445 & $\mathbf{0 . 8 2 4}$ & \\
SCS & 0.661 & 0.577 & 0.492 & 0.476 & 0.601 & 0.350 & $\mathbf{0 . 8 8 8}$ \\
\hline
\end{tabular}

Table 2. AVE Square Root (Fornell-Larcker criterion)

Note: IACB-AIS: intention to adopt CB-AIS, OR: organization readiness, TMS: top management support, SC: security concern, PU: perceived usefulness, CP: competitive pressure, SCS: supplier computing support.

\subsection{Structural model}

The accuracy of the structural model is assessed using R2, which refers to the coefficient of determination and the path coefficient significance level (Hair Jr. et al., 2021). The adjusted R2 value for IACB-AIS was found to be 0.45 , which means that $45 \%$ of the IACB-AIS variance was explained by the factors, indicating the statistical significance of the proposed model. The study also examined the relationships of endogenous and exogenous variables through the use of path coefficient $(\beta)$ and t-statistics. Table 3 contains a summarized version of the hypothesis results. It clearly illustrates that hypotheses $\mathrm{H} 1-\mathrm{H} 6$ are statistically significant $(\mathrm{PU} \rightarrow \mathrm{IACB}-\mathrm{AIS}, \quad \beta=0.168, \mathrm{t}=3.842 ; \quad \mathrm{SC} \rightarrow \mathrm{IACB}-\mathrm{AIS}, \quad \beta=-0.167$, $\mathrm{t}=3.751$; TMS $\rightarrow$ IACB-AIS, $\beta=0.157, \mathrm{t}=3.880$; OR $\rightarrow$ IACB-AIS, $\beta=0.266$, $\mathrm{t}=5.080$; $\mathrm{CP} \rightarrow$ IACB-AIS, $\beta=0.284, \mathrm{t}=5.105$; and SCS $\rightarrow$ IACB-AIS, $\beta=0.088, \mathrm{t}=2.278$, respectively). The results empirically proved the significance of the hypothesized 
relationships between $\mathrm{PU}, \mathrm{SC}$, TMS, OR, CP, SCS, and IACB-AIS in the context of SMEs in Jordan.

\begin{tabular}{llcccc}
\hline $\begin{array}{c}\text { Hypothesis } \\
\text { No. }\end{array}$ & Path & $\boldsymbol{\beta}$ & T-Value & P-Value & Decision \\
\hline H1 & PU $\rightarrow$ IACB-AIS & 0.168 & $3.842^{* *}$ & 0.000 & Accepted \\
H2 & SC $\rightarrow$ IACB-AIS & -0.167 & $3.751^{* *}$ & 0.000 & Accepted \\
H3 & TMS $\rightarrow$ IACB-AIS & 0.157 & $3.880^{* *}$ & 0.000 & Accepted \\
H4 & OR $\rightarrow$ IACB-AIS & 0.266 & $5.080^{* *}$ & 0.000 & Accepted \\
H5 & CP $\rightarrow$ IACB-AIS & 0.284 & $5.105^{* *}$ & 0.000 & Accepted \\
H6 & SCS $\rightarrow$ IACB-AIS & 0.088 & $2.278^{*}$ & 0.024 & Accepted \\
\hline \multicolumn{7}{l}{ Table 3. Results of Hypothesis Testing of the Direct Relationship Model }
\end{tabular}

Note: IACB-AIS: intention to adopt CB-AIS, OR: organization readiness, TMS: top management support, SC: security concern, PU: perceived usefulness, CP: competitive pressure, SCS: supplier computing support; *: significant at $\mathrm{p}<0.05$; and $* *$ : significant at $\mathrm{p}<0.01$.

\section{DISCUSSION}

\subsection{Technology context}

The finding revealed PU to be a significant driver of IACB-AIS among the SMEs in Jordan, contrary to the result reported by Alkhater et al. (2018) and Low et al. (2011), who found that firms are unaware of the usefulness and advantages of using CB systems. On the other hand, studies like Khayer et al. (2020); Oliveira et al. (2014); and Makena (2013) supported the finding, with claims that organizations are aware and do recognize the usefulness of CB system adoption and usage. The current study supports the SMEs' primary emphasis on the potential advantages of the systems, including generating new business opportunities, mitigating IT/IS costs, enhancing productivity, and increasing operational efficiency. Such advantages cannot be provided through the use of traditional systems and technologies. Moving on to SC, the result showed that it prevents the IACB-AIS among SMEs in Jordan, consistent with prior studies concerning the acceptance of technology-based services (Usman et al., 2019). In other words, SC may hinder the intention toward adoption and could have a hand in preventing the adoption among 
SMEs. Hence, SC should be considered to ensure CB-AIS adoption among SMEs. In the initial adoption-decision process, potential adopters need to be concerned about $\mathrm{SC}$ as opposed to the quality of source and services. CB-AIS providers should be aware that a lack of SC remains a barrier toward CB-AIS adoption.

\subsection{Organization context}

This work presents actual evidence of the importance of managerial support through resource allocation and involvement in the work process so that the adoption decision of the technology/system is accelerated. This notion holds true for CB-AIS and is reflected in Lutfi et al. (2017) and Lutfi et al. (2020), who found TMS to be one of the top organizational factors driving new innovation/technology adoption and usage. Currently, the market dynamic environment is urging businesses to ensure TMS in every critical decision (Khayer et al., 2020), given that without such support, the adoption or acceptance of a new technology/system like CB-AIS may fail (Ahani et al., 2017). Moreover, the study revealed a positive and strong influence of OR on IACB-AIS among SMEs in Jordan, which is aligned with the findings of prior studies (Lutfi et al., 2016; Alshirah et al., 2021), where a significant and positive relationship between OR and adoption of cloud computing services was identified. The study also found that PU and financial and technical readiness of the organization make for a successful CB-AIS adoption.

\subsection{Environment context}

The support of SPS plays a positive and direct impact in IACB-AIS in the context of Jordanian SMEs. This finding suggests that SPS can support SMEs, who suffer from insufficient technological, skilled human, and financial resources for maintaining and developing their infrastructure, which eventually promote them to accept/adopt CB systems. SMEs' decision to adopt CB systems is greatly subjective to the trust and promises developed by cloud computing providers in terms of providing distinctive services and keeping in touch with them. SME managers believe the support of the service supplier is one of the most influential factors, particularly if the latter assures SMEs that they will not experience any future issues (data losses and/or availability) and will obtain continuous service testing and maintenance. Notably, CP was found as the most significant determinant of IACBAIS by SMEs in Jordan. The positive and significant influence of CP in technology adoption/acceptance is also supported by several similar studies (Lutfi et al., 2016; Low et al., 2011). In other words, when SMEs face CP, they have no choice but to 
adopt/accept the innovation. In both settings, the adoption of CB-AIS for SMEs takes place when they find that such adoption preserves their competitiveness and/or maintains their competitive position.

\section{CONCLUSION}

This work aimed to identify the factors influencing the IACB-AIS of SMEs in Jordan. The research findings revealed that PU, SC, TMS, OR, CP, and SCS have positive and significant impacts on the IACB-AIS in Jordanian SMEs. These findings offer reliable information for computing providers of CB-AIS in Jordan to make business-related decisions. CB services consist of emerging technologies, which are still considered as disruptive. Businesses are not well aware of the CB systems' potential utilizations, especially in developing nations such as Jordan. Thus, computing providers and suppliers should assume numerous procedures to increase the awareness of target users regarding these technological advantages through promotional seminars and workshops. They should also focus on easy-touse interfaces and functional utilities while designing CB systems for SMEs so that adopters with partial technology knowledge and experiences can use/adopt these systems easily. In addition, clear navigation or instructions must be offered to assist SME users in the smooth operation of CB systems, which would be the key to their IACB-AIS and increase their confidence in using CB systems such as CB-AIS.

This work also contributes significantly to the research on behavioral intention of adopting/using cloud computing based on the TOE model. However, this work has certain limitations that lead to the future agenda of studies. First, data were collected from a single country (Jordan). Thus, it is suggested that future work apply a sample from similar countries to validate the framework. Second, the current research developed the framework by considering important constructs from three dimensions. Further works can extend the conceptual framework by including other appropriate constructs under the three key contexts. Third, the present model was evaluated with one-time cross-sectional data. Future studies could test the model by using longitudinal data over a period. Fourth, the research attempted to examine IACB-AIS in SMEs from an organizational perspective. Future works may consider the perspectives of individuals (employees) and cloud technology providers to obtain a broader understanding of the cloud computing adoption/acceptance process. Fifth, the applications of cloud computing-based technologies are still new in Jordan, particularly in the field of AIS. Further work needs to apply large-scale 
samples to ensure representativeness for the study. Finally, this research only explored organizational IACB-AIS in the context of SMEs. The evaluation of the post adoption stage (successful adoption/implementation) of such technology could be a prior potential for future studies.

Funding: This research was funded by the Deanship of Scientific Research at King Faisal University, grant no. 206025.

Acknowledgments: The author acknowledges the Deanship of Scientific Research at King Faisal University for their financial support under Nasher Track (grant no. 206025).

Conflicts of Interest: The author declares no conflict of interest.

\section{REFERENCES}

Abbas, H. A., \& Hamdy, H. I. (2015). Determinants of continuance intention factor in Kuwait communication market: Case study of Zain-Kuwait. Computers in Human Behavior, 49, 648-657. https://doi.org/10.1016/j.chb.2015.03.035

Al Amri, M. M., \& Almaiah, M. A. (2020). The use of mobile gamification technology for sustainability learning in Saudi higher education. International Journal of Advanced Trends in Computer Science and Engineering, 9(5), 82368244. https://doi.org/10.30534/ijatcse/2020/191952020

Ahani, A., Rahim, N. Z. A., \& Nilashi, M. (2017). Forecasting social CRM adoption in SMEs: A combined SEM-neural network method. Computers in Human Behavior, 75, 560-578. https://doi.org/10.1016/j.chb.2017.05.032

Al-dmour, A., Al-dmour, R., \& Masa'deh, R. (2016). Interrelated factors influencing the adoption decision of AIS applications by SMEs in Jordan. International Business Research, 9(10), 46-62. https://doi.org/10.5539/ ibr.v9n10p46

Alkhater, N., Walters, R., \& Wills, G. (2018). An empirical study of factors influencing cloud adoption among private sector organisations. Telematics and Informatics, 35(1), 38-54. https://doi.org/10.1016/j.tele.2017.09.017 
Al-Khasawneh, A. L., Al-Jammal, H. R., \& Al-Khasawneh, M. (2015). Human resources stature from the islamic perspective: Deductive analytical study from Qur'an. International Journal of Academic Research in Business and Social Sciences, 5(12), 241-262. https://doi.org/10.6007/IJARBSS/v5-i12/1947

Almaiah, M. A., Al-Khasawneh, A., Althunibat, A., \& Almomani, O. (2021). Exploring the main determinants of mobile learning application usage during Covid-19 pandemic in Jordanian universities. In Emerging Technologies During the Era of COVID-19 Pandemic 16(3), 275-290.

Alshira'h, A. F. (2019). The Effect of Peer Influence on Sales Tax Compliance among Jordanian SMEs. International Journal of Academic Research in Business and Social Sciences, 9(3), 710-721. https://doi.org/10.6007/IJARBSS/v9-i3/5737

Alshira'h, A. F., Al-Shatnawi, H. M., Al-Okaily, M., Lutfi, A., \& Alshirah, M. H. (2020). Do public governance and patriotism matter? Sales tax compliance among small and medium enterprises in developing countries: Jordanian evidence. EuroMed Journal of Business. 16(4), 431-455. https://doi.org/10.1108/EMJB-012020-0004

Alshirah, A., Magablih, A., \& Alsqour, M. (2021). The effect of tax rate on sales tax compliance among Jordanian public shareholding corporations. Accounting, 7(4), 883-892. https://doi.org/10.5267/j.ac.2021.1.020

Alshira'h, A., Alsqour, M., Lutfi, A., Alsyouf, A., \& Alshirah, M. (2020). A SocioEconomic Model of Sales Tax Compliance, Economies, 8 (4), 88. https://doi.org/10.3390/economies 8040088

Alshira'h, A, and Abdul-Jabbar, H. (2020). Moderating role of patriotism on sales tax compliance among Jordanian SMEs. International Journal of Islamic and Middle Eastern Finance and Management, 13: 389-415. https://doi.10.1108/IMEFM-04-2019-0139

Alshirah, M., Lutfi, A., Alshirah, A., Saad, M., Ibrahim, N., \& Mohammed, F. (2021). Influences of the environmental factors on the intention to adopt cloud based accounting information system among SMEs in Jordan. Accounting, 7(3), 645-654. https://doi.org/10.5267/j.ac.2020.12.013

Alqudah, H., Amran, N. \& Hassan, H. (2019). Factors affecting the internal auditors' effectiveness in the Jordanian public sector: The moderating effect of task complexity. EuroMed Journal of Business, 14(3), 251-273. https://doi.org/10.1108/EMJB-03-2019-0049 
Al-Okaily, M., Lutfi, A., Alsaad, A., Taamneh, A. \& Alsyouf, A. (2020a). The Determinants of Digital Payment Systems' Acceptance under Cultural Orientation Differences: The Case of Uncertainty Avoidance. Technology in society, 63, 1-15, 101367. https://doi.org/10.1016/j.techsoc.2020.101367

Al-Okaily, M., Alqudah, H., Matar, A., Lutfi, A., \& Taamneh, A. (2020b). Dataset on the Acceptance of e-learning System among Universities Students' under the COVID-19 Pandemic Conditions. Data in Brief, 32, 1-5, 106176. https://doi.org/10.1016/j.dib.2020.106176

Al-Okaily, M., Alqudah, H., Matar, A., Lutfi, A. A. \& Taamneh, A. (2020c). Impact of Covid-19 Pandemic on Acceptance of E-learning System in Jordan: A Case of Transforming the Traditional Education Systems, Humanities and social Sciences Review, 6 (4), 840-851. https://doi.org/10.18510/hssr.2020.8483

Alsyouf, A. (2021). Self-Efficacy and Personal Innovativeness Influence on Nurses Beliefs about EHRs Usage in Saudi Arabia: Conceptual Model. International Journal of Management (IJM), 12(3), 1049-1058. https://doi.org/10.34218/ IJM.12.3.2021.096

Alsyouf, A., \& Ishak, A. K. (2018). Understanding EHRs continuance intention to use from the perspectives of UTAUT: practice environment moderating effect and top management support as predictor variables. International Journal of Electronic Healthcare, 10(1-2), 24-59. https://doi.org/10.1504/IJEH.2018.092175

Alsyouf, A., Masa'deh, R., Albugami, M., Al-Bsheish, M., Lutfi, A. \& Alsubahi, N. (2021). Risk of Fear and Anxiety in Utilising Health App Surveillance Due to COVID-19: Gender Differences Analysis. Risks 9, 179. https:// doi.org/10.3390/risks9100179

Aini, Q., Anoesyirwan, A., \& Ana, Y. (2020). Effect of Cloud Accounting as income statement on Accountant Performance. Aptisi Transactions on Management (ATM), 4(1), 13-21. DOI: https://doi.org/10.33050/atm.v4i1.920

Asatiani, A., Penttinen, E., (2019). Constructing continuities in virtual work environments: a multiple case study of two firms with differing degrees of virtuality. Information Systems Journal. 29, 484-513. https://doi.org/ $10.1111 /$ isj. 12217 
Asatiani, A., Apte, U., Penttinen, E., Rönkkö, M., \& Saarinen, T. (2019). Impact of accounting process characteristics on accounting outsourcing-Comparison of users and non-users of cloud-based accounting information systems. International Journal of Accounting Information Systems, 34, 100419. https://doi.org/10.1016/ j.accinf.2019.06.002

Awa, H. O., Ukoha, O., \& Emecheta, B. C. (2016). Using TOE theoretical framework to study the adoption of ERP solution. Cogent Business \& Management, 3(1), 1196571. https://doi.org/10.1080/23311975.2016.1196571

Bani-Khalid, T., Alshira'h, A. F., \& Alshirah, M. H. (2022). Determinants of Tax Compliance Intention among Jordanian SMEs: A Focus on the Theory of Planned Behavior. Economies, 10(2), 1-20. https://doi.org/ 10.3390/economies10020030

Berl, A., Gelenbe, E., Di Girolamo, M., Giuliani, G., De Meer, H., Dang, M. Q., \& Pentikousis, K. (2010). Energy-efficient cloud computing. The computer journal, 53(7), 1045-1051. https://doi.org/10.1093/comjnl/bxp080

Buntin, M. B., Burke, M. F., Hoaglin, M. C., \& Blumenthal, D. (2011). The benefits of health information technology: a review of the recent literature shows predominantly positive results. Health affairs, 30(3), 464-471. https://doi.org/10.1377/hlthaff.2011.0178

Daoud, L., \& Ibrahim, M. (2019). Antecedents and Impacts of Electronic Procurement Usage among Jordanian Large Firms. Journal of Advanced Research in Business and Management Studies, 14(1), 52-65. https://doi.org/10. akademiabaru.com/doc/ARBMSV14_N1_P52_65

Davis, F. D. (1989). Perceived usefulness, perceived ease of use, and user acceptance of information technology. MIS quarterly, 13(3), 319-340. https://doi.org/10.2307/249008

Elkaseh, A. M., Wong, K. W., \& Fung, C. C. (2016). Perceived ease of use and perceived usefulness of social media for e-learning in Libyan higher education: A structural equation modeling analysis. International Journal of Information and Education Technology, 6(3), 192. https://doi.org/10.7763/IJIET.2016.V6.683

Faccia, A., \& Petratos, P. (2021). Blockchain, Enterprise Resource Planning (ERP) and Accounting Information Systems (AIS): Research on e-Procurement and System Integration. Applied Sciences, 11(15), 1-17. https://doi.org/10.3390/ app11156792 
Fathian, M., Akhavan, P., \& Hoorali, M. (2008). E-readiness assessment of nonprofit ICT SMEs in a developing country: The case of Iran. Technovation, 28(9), 578-590. https://doi.org/10.1016/j.technovation.2008.02.002

Fillis, I., Johannson, U., \& Wagner, B. (2004). Factors impacting on e-business adoption and development in the smaller firm. International Journal of Entrepreneurial Behavior \& Research. https://doi.org/10.1108/135525504 10536762

Frambach, R. T., Barkema, H. G., Nooteboom, B., \& Wedel, M. (1998). Adoption of a service innovation in the business market: an empirical test of supply-side variables. Journal of business research, 41(2), 161-174. https://doi.org/10.01482963(97)00005-2

Fornell, C., \& Larcker, D. F. (1981). Evaluating structural equation models with unobservable variables and measurement error. Journal of marketing research, 18(1), 39-50.

Gutierrez, A., Boukrami, E., \& Lumsden, R. (2015). Technological, organisational and environmental factors influencing managers' decision to adopt cloud computing in the UK. Journal of Enterprise Information Management, 28(6), 788807. https://doi.org/10.1108/JEIM-01-2015-0001

Hair, J. F., Risher, J. J., Sarstedt, M., \& Ringle, C. M. (2019). When to use and how to report the results of PLS-SEM. European business review, 31(1), 2-24. https://doi.org/10.1108/EBR-11-2018-0203

Hair Jr, J. F., Hult, G. T. M., Ringle, C. M., \& Sarstedt, M. (2021). A primer on partial least squares structural equation modeling (PLS-SEM). Sage publications.

Henseler, J., Ringle, C. M., \& Sarstedt, M. (2015). A new criterion for assessing discriminant validity in variance-based structural equation modeling. Journal of the academy of marketing science, 43(1), 115-135. https://doi.org/10.1007/s11747014-0403-8

Hsu, P. F., Ray, S., \& Li-Hsieh, Y. Y. (2014). Examining cloud computing adoption intention, pricing mechanism, and deployment model. International Journal of Information Management, 34(4), 474-488. https://doi.org/10.1016/ j.ijinfomgt.2014.04.006

Iacovou, C. L., Benbasat, I., \& Dexter, A. S. (1995). Electronic data interchange and small organizations: Adoption and impact of technology. MIS quarterly, 12(2), 465-485. 
Jamal, A., \& Sharifuddin, J. (2015). Perceived value and perceived usefulness of halal labeling: The role of religion and culture. Journal of Business research, 68(5), 933-941. https://doi.org/10.1016/j.jbusres.2014.09.020

Jeyaraj, A., Rottman, J. W., \& Lacity, M. C. (2006). A review of the predictors, linkages, and biases in IT innovation adoption research. Journal of information technology, 21(1), 1-23. https://doi.org/10.1057/palgrave.jit.2000056

Khayer, A., Talukder, M. S., Bao, Y., \& Hossain, M. N. (2020). Cloud computing adoption and its impact on SMEs' performance for cloud supported operations: A dual-stage analytical approach. Technology in Society, 60, 101225. https://doi.org/10.1016/j.techsoc.2019.101225

Le, O., \& Cao, Q. (2020). Examining the technology acceptance model using cloudbased accounting software of Vietnamese enterprises. Management Science Letters, 10(12), 2781-2788. https://doi.org/10.5267/j.msl.2020.4.032

Lutfi, A. (2021). Understanding Cloud Based Enterprise Resource Planning Adoption among SMEs in Jordan. Journal of Theoretical and Applied Information Technology, 99(24), 5944-5953.

Lutfi, A. (2020). Investigating the moderating effect of Environment Uncertainty on the relationship between institutional factors and ERP adoption among Jordanian SMEs, Journal of Open Innovation: Technology, Market, and Complexity, 6(3), 91. https://doi.org/10.3390/joitmc6030091

Lutfi, A. A., Idris, K. M., \& Mohamad, R. (2017). AIS usage factors and impact among Jordanian SMEs: The moderating effect of environmental uncertainty. Journal of Advanced Research in Business and Management Studies, 6(1), 24-38.

Lutfi, A. A., Idris, K. M., \& Mohamad, R. (2016). The influence of technological, organizational and environmental factors on accounting information system usage among Jordanian small and medium-sized enterprises. International Journal of Economics and Financial Issues, 6(7S), 240-248.

Lutfi, A., Al-Okaily, M., Alsyouf, A., Alsaad, A., \& Taamneh, A. (2020). The Impact of AIS Usage on AIS Effectiveness among Jordanian SMEs: A Multi Group Analysis of the Role of Firm Size. Global Business Review, 21(1), 1-19 https://doi.org/10.1177/0972150920965079

Lutfi, A., Al-Okaily, M., Alshirah, M.H., Alshira'h, A.F., Abutaber, T.A., \& Almarashdah, M.A. (2021). Digital Financial Inclusion Sustainability in Jordanian Context. Sustainability, 13, 6312. https:// doi.org/10.3390/su13116312 
Lutfi, A., Alsyouf, A., Almaiah, M. A., Alrawad, M., Abdo, A. A. K., AlKhasawneh, A. L., \& Saad, M. (2022). Factors Influencing the Adoption of Big Data Analytics in the Digital Transformation Era: Case Study of Jordanian SMEs. Sustainability, 14(3), 1802. https://doi.org/10.3390/su14031802

Low, C., Chen, Y., \& Wu, M. (2011). Understanding the determinants of cloud computing adoption. Industrial management \& data systems. 111(7), 1006-1023. https://doi.org/10.1108/02635571111161262

Ma, D., Fisher, R., \& Nesbit, T. (2021). Cloud-based client accounting and small and medium accounting practices: Adoption and impact. International Journal of $\begin{array}{llll}\text { Accounting Information } & \text { Systems, } & 41, & 100513 .\end{array}$ https://doi.org/10.1016/j.accinf.2021.100513

Makena, J. N. (2013). Factors that affect cloud computing adoption by small and medium enterprises in Kenya. International Journal of Computer Applications Technology and Research, 2(5), 517-521.

Maqueira-Marín, J. M., Bruque-Cámara, S., \& Minguela-Rata, B. (2017). Environment determinants in business adoption of Cloud Computing. Industrial Management \& Data Systems. 117(1), 28-246. https://doi.org/10.1108/IMDS-112015-0468

Misra, S. C., \& Mondal, A. (2011). Identification of a company's suitability for the adoption of cloud computing and modelling its corresponding Return on Investment. Mathematical and Computer Modelling, 53(3-4), 504-521. https://doi.org/10.1016/j.mcm.2010.03.037

Oliveira, T., Martins, R., Sarker, S., Thomas, M., \& Popovič, A. (2019). Understanding SaaS adoption: The moderating impact of the environment context. International Journal of Information Management, 49, 1-12. https://doi.org/10.1016/j.ijinfomgt.2019.02.009

Oliveira, T., Thomas, M., \& Espadanal, M., (2014). Assessing the determinants of cloud computing adoption: an analysis of the manufacturing and services sectors. Information Management, 55, 497-510. https://doi.org/10.1016/j.im.2014.03.006

Popivniak, Y. (2019). Cloud-Based Accounting Software: Choice Options In The Light Of Modern International Tendencies. Baltic Journal of Economic Studies, 5(3), 170-177. https://doi.org/10.30525/2256-0742/2019-5-3-170-177 
Ramdani, B., Kawalek, P., \& Lorenzo, O. (2009). Predicting SMEs' adoption of enterprise systems. Journal of enterprise information management, 22(1/2), 10-24. https://doi.org/10.1108/17410390910922796

Reinartz, W., Haenlein, M., \& Henseler, J. (2009). An empirical comparison of the efficacy of covariance-based and variance-based SEM. International Journal of research in Marketing, 26(4), 332-344.

Rohde, F.H., (2004). IS/IT outsourcing practices of small- and medium-sized manufacturers. International Journal of Accounting Information Systems. 5, 429451. https://doi.org/10.1016/j.accinf.2004.04.006

Rogers, E. M. (1995). Lessons for guidelines from the diffusion of innovations. The Joint Commission journal on quality improvement, 21(7), 324-328. DOI: https://doi.org/10.1016/S1070-3241 (16)30155-9

Sahandi, R., Alkhalil, A., \& Opara-Martins, J. (2012, October). SMEs' perception of cloud computing: Potential and security. In Working Conference on Virtual Enterprises, 186-195. Springer, Berlin, Heidelberg. https://doi.org/10.1007/978-3642-32775-9_19.pdf

Salum, K. H., \& Rozan, M. Z. A. (2016). Exploring the challenge impacted SMEs to adopt cloud ERP. Indian Journal of Science and Technology, 9(45), 1-8. https://doi.org/10.17485/ijst/2016/v9i45/100452

Siamagka, N. T., Christodoulides, G., Michaelidou, N., \& Valvi, A. (2015). Determinants of social media adoption by B2B organizations. Industrial Marketing Management, 51, 89-99. https://doi.org/10.1016/j.indmarman.2015.05.005

Simatupang, T. M., \& Sridharan, R. (2005). The collaboration index: a measure for supply chain collaboration. International Journal of Physical Distribution \& Logistics Management. https://doi.org/10.1108/09600030510577421

Scupola, A. (2003). The adoption of Internet commerce by SMEs in the south of Italy: An environmental, technological and organizational perspective. Journal of Global Information Technology Management, 6(1), 52-71. https://doi.org/10.1080/1097198X.2003.10856343

Sultan, N.A. (2011). Reaching for the "Cloud": how SMEs can manage. International journal of information management. 31, 272-278. https://doi.org/10.1016/j.ijinfomgt.2010.08.001 
Sutthikun, W., Thapo, R., \& Sahayrak, K. (2018). Accounting in the Cloud. International Journal of Integrated Education and Development, 3(2), 19-27.

Thong, J. Y. (1999). An integrated model of information systems adoption in small businesses. Journal of management information systems, 15(4), 187-214. https://doi.org/10.1080/07421222.1999.11518227

Usman, U. M. Z., Ahmad, M. N., \& Zakaria, N. H. (2019). The Determinants of Adoption of Cloud-Based ERP of Nigerian's SMES Manufacturing Sector Using Toe Framework and Doi Theory. International Journal of Enterprise Information Systems (IJEIS), 15(3), 27-43. https://doi.org/10.4018/IJEIS.2019070102

Woodside, A. G., \& Biemans, W. (2005). Managing relationships, networks, and complexity in innovation, diffusion, and adoption processes. Journal of Business \& Industrial Marketing, 20(7), 335-338. https://doi.org/10.1108/08858620510628560

Zhu, H., Yang, D., Yu, G., Zhang, H., \& Yao, K. (2006). A simple hydrothermal route for synthesizing SnO2 quantum dots. Nanotechnology, 17(9), 2386. https://doi.org/10.1088/0957-4484/17/9/052 